\title{
Association of Noise Annoyance with Measured Renal Hemodynamic Changes
}

\author{
Dennis Kannenkeril ${ }^{a}$ Susanne Jung ${ }^{\mathrm{a}, \mathrm{b}}$ Christian Ott ${ }^{\mathrm{a}, \mathrm{c}}$ Kristina Striepe $^{\mathrm{a}}$ \\ Julie Kolwelter ${ }^{a}$ b Roland E. Schmieder ${ }^{a}$ Agnes Bosch $^{a}$ \\ aDepartment of Nephrology and Hypertension, University Hospital Erlangen, Friedrich-Alexander-University

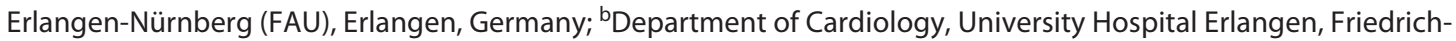 \\ Alexander-University Erlangen-Nürnberg (FAU), Erlangen, Germany; ' Department of Nephrology and Hypertension, \\ Paracelsus Medical University, Nürnberg, Germany
}

\section{Keywords}

Noise · Annoyance $\cdot$ Renal hemodynamics $\cdot$ Renal clearance Sympathetic activity

\begin{abstract}
Background: Chronic mental stress is recognized as a modifiable risk factor for cardiovascular disease. The aim of this study was to demonstrate that noise annoyance-induced stress is associated with changes in renal hemodynamics. Methods: Renal hemodynamic parameters were measured using steady-state input clearance with infusion of para-aminohippuric acid and inulin in individuals with normal, high normal, and elevated blood pressure. All individuals ranked subjective annoyance due to noise in everyday life on a 7-grade Likert scale. The median of all rankings was used as a cutoff point to divide the group into noise-annoyed and non-noise-annoyed individuals. Different renal hemodynamic parameters were calculated based on the Gomez equation. Results: Noise-annoyed individuals $(n=58)$ showed lower renal plasma flow $(599 \pm 106 \mathrm{vs.} 663 \pm 124 \mathrm{~mL} /$ $\min , p=0.009)$, lower renal blood flow $(1,068 \pm 203$ vs. 1,172 $\pm 225 \mathrm{~mL} / \mathrm{min}, p=0.047)$, higher filtration fraction $(22.7 \pm 3.3$ vs. $21.3 \pm 3.0, p=0.012)$, higher renal vascular resistance $(88.9 \pm 25.6$ vs. $75.8 \pm 22.9 \mathrm{~mm} \mathrm{Hg} /[\mathrm{mL} / \mathrm{min}], p=0.002)$, and higher resistance of afferent arteriole (2,439.5 $\pm 1,253.4$ vs.
\end{abstract}

karger@karger.com www.karger.com/kbr

Karger $\stackrel{\text { ' }}{5}$

GOPEN ACCESS
(C) 2021 The Author(s)

Published by S. Karger AG, Basel

This is an Open Access article licensed under the Creative Commons Attribution-NonCommercial-4.0 International License (CC BY-NC) (http://www.karger.com/Services/OpenAccessLicense), applicable to the online version of the article only. Usage and distribution for commercial purposes requires written permission.
$1,849.9 \pm 1,242.0$ dyn s$\left.^{-1} \mathrm{~cm}^{-5}, p=0.001\right)$ compared to nonnoise-annoyed individuals $(n=55)$. There was no difference in measured glomerular filtration rate $(133 \pm 11.8$ vs. $138 \pm$ $15 \mathrm{~mL} / \mathrm{min}, p=0.181)$, resistance of efferent arteriole $(2,419.4$ \pm 472.2 vs. $2,245.8 \pm 370.3$ dyn s$\left.^{-1} \mathrm{~cm}^{-5}, p=0.060\right)$, and intraglomerular pressure $(64.0 \pm 3.1$ vs. $64.6 \pm 3.5 \mathrm{~mm} \mathrm{Hg}, p=$ 0.298 ) between the groups. After adjusting for age, renal plasma flow, renal blood flow, and renal vascular resistance remained significantly different between the groups, with a trend in increased afferent arteriolar resistance and filtration fraction. Conclusion: In this study, noise annoyance was associated with reduced renal perfusion attributed to increased renal vascular resistance predominantly at the afferent site. Long-term consequences of this renal hemodynamic pattern due to noise annoyance need to be investigated.

(C) 2021 The Author(s)

Published by S. Karger AG, Basel

\section{Introduction}

Chronic mental stress is recognized as a modifiable risk factor for cardiovascular disease (CVD) [1-3]. Cardiovascular morbidity in adulthood has been found to be attributed to stressors of early life [4]. The INTERHEART study demonstrated that exposure to chronic mental stress is strongly associated with the risk of coronary heart 
disease consistently across different geographic regions independent of conventional risk factors [5]. This association was as strong as that for cigarette smoking, elevated blood pressure (BP), and cholesterol. Similar associations have been noticed in animal experiments, especially in monkeys $[6,7]$. Coronary artery disease was found to be more profound in monkeys in a more stressful social environment compared to control animals without exposure to stress. Interestingly, exacerbated coronary artery disease was not attributed to corresponding alterations in serum lipids, BP, or fasting glucose concentration, pointing towards other possible mechanisms than classic mechanisms involved in the development of arteriosclerosis [8].

Noise annoyance is widely recognized as a form of mental stress [9]. A representative study of the German Environment Agency shows that $75 \%$ of the German population feel annoyed by road traffic noise from their living environment [10]. WHO Europe described annoyance to be the second major health effect of environmental noise after sleep disturbance [11]. It has been estimated that disability-adjusted life years lost from environmental noise are 61,000 years for CVD and 654,000 years for annoyance in Western European countries. Noise annoyance has been shown to be linked with increased risk of CVD, and the evidence of this association has increased over years $[12,13]$. The activation of the autonomic and endocrine system by noise annoyance is proposed to lead to pathophysiologic changes of vessels contributing to initiation and progression of CVD $[14,15]$. A pathologic relationship between chronic mental stress and kidneys has been suggested $[16,17]$, since sympathetic nerves innervate all segments of the kidney, and neural mechanisms regulate sodium and water retention [18]. However, this area of research is widely unexplored.

We therefore analyzed in a cross-sectional study the influence of noise annoyance on renal hemodynamics, that is, whether annoyance-induced stress is associated with changes in renal hemodynamics. If so, this environmental stressor may act as a risk factor for the development or progression of chronic kidney disease (CKD) and CVD, along with known risk factors such as diabetes mellitus and arterial hypertension.

\section{Methods}

\section{Study Design}

This is a cross-sectional, single-center clinical study conducted from March 2016 till January 2018. The primary objective was to compare the renal hemodynamic pattern between individuals an- noyed and not annoyed to noise. This study was performed at the Clinical Research Unit of the Department of Nephrology and Hypertension, University of Erlangen, Germany (www.clinicaltrials. gov: NCT02783456). The study protocol was approved by the Ethics Committee of the University Erlangen (Application No. 68_16B) and performed in accordance with the Declaration of Helsinki and the principles of Good Clinical Practice guidelines. Individuals were recruited by advertising in local newspapers in the area of Erlangen-Nürnberg, Germany, or by referral of the primary care physician to our outpatient clinic. All individuals provided written informed consent prior to inclusion in the study.

\section{Study Population}

One hundred thirteen nonsmoking, male Caucasian individuals with normal, high normal, and elevated $\mathrm{BP}$ were included in the study. In individuals with high $\mathrm{BP}$, the antihypertensive medication (no more than one antihypertensive substance of either ACE inhibitor, $\mathrm{ARB}$, or calcium-channel antagonist) at the screening visit underwent a washout period of 2 weeks before study inclusion. Office BP was taken in a standardized fashion according to guideline recommendations [19]. Main exclusion criteria were secondary hypertension, severe primary hypertension (systolic BP $\geq 180 \mathrm{~mm} \mathrm{Hg}$ and/or diastolic BP $\geq 110 \mathrm{~mm} \mathrm{Hg}$ ), history of hypertensive encephalopathy or intracerebral hemorrhage, diabetes mellitus, myocardial infarction, unstable angina pectoris, percutaneous coronary intervention, or heart failure within the previous 6 months. Patients with any other significant disease were also excluded.

\section{Assessment of Noise Annoyance}

All individuals ranked subjective annoyance due to noise in everyday life on a 7 -grade Likert scale. The median of all rankings was used as a cutoff point to divide the group into noise-annoyed and non-noise-annoyed individuals.

\section{Assessment of Renal Hemodynamics}

The assessment of renal hemodynamic parameters has been described in detail in former studies [20-25]. Briefly, glomerular filtration rate (GFR) and renal plasma flow (RPF) were assessed using the constant-infusion input clearance technique with infusion of inulin (Sinistrin, Inutest ${ }^{\circledR} 25 \%$ Amp; Fresenius Kabi, Austria) and para-aminohippuric acid (Sodium-para-aminohippurate Injection ${ }^{\circledR} 10 \%$; Daiichi-Sankyo, Tokyo, Japan), respectively. After bolus infusion of para-aminohippurate and inulin over $15 \mathrm{~min}$ and a subsequent constant infusion over $105 \mathrm{~min}$, a steady state between input and renal excretion of the tracer substances is achieved. Duplicate blood samples were collected for the assessment of RPF and GFR. Filtration fraction was calculated as GFR/ $\mathrm{RPF} \times 100$. Renal blood flow was calculated as RPF/(1 - hematocrit). Renal vascular resistance was calculated as mean arterial BP/ renal blood flow $\times 1,000$. Intraglomerular pressure and resistances of the afferent and efferent arterioles were calculated based on the Gomez equation [26], which has been applied in previous studies $[21,23,25,27]$.

\section{Statistical Methods}

Data are given as mean with standard deviation. Normal distribution of data was confirmed by the Kolmogorov-Smirnov test and histogram before further analysis. Normally distributed data were compared by unpaired Student $t$ tests. For not normally dis- 
Table 1. Clinical characteristics of study populations

\begin{tabular}{lccc}
\hline & $\begin{array}{c}\text { Non-noise-annoyed } \\
\text { individuals }(n=55)\end{array}$ & $\begin{array}{c}\text { Noise-annoyed } \\
\text { individuals }(n=58)\end{array}$ & $p$ value \\
\hline Age, years & $29.9 \pm 9.5$ & $34 \pm 9.7$ & 0.023 \\
BMI, kg/m ${ }^{2}$ & $24.3 \pm 2.9$ & $25.3 \pm 3.5$ & 0.078 \\
Systolic BP, mm Hg & $129.4 \pm 12.2$ & $132.8 \pm 13.2$ & 0.154 \\
Diastolic BP, mm Hg & $77.2 \pm 10.7$ & $79.9 \pm 10.8$ & 0.178 \\
Mean BP, mm Hg & $94.6 \pm 10.3$ & $97.5 \pm 10.2$ & 0.125 \\
HR, bpm & $66.8 \pm 9.2$ & $70.6 \pm 10.5$ & 0.039 \\
Serum creatinine, mg/dL & $0.95 \pm 0.12$ & $0.93 \pm 0.12$ & 0.404 \\
eGFR (CKD-EPI), mL/min per $1.73 \mathrm{~m}^{2}$ & $106.2 \pm 14.4$ & $105.2 \pm 14.6$ & 0.700 \\
Serum cystatin C, mg/L & $0.77 \pm 0.07$ & $0.77 \pm 0.14$ & 0.513 \\
eGFR (cystatin C), mL/min per $1.73 \mathrm{~m}^{2}$ & $109.5 \pm 12.5$ & $105.8 \pm 15$ & 0.161 \\
BUN, mg/dL & $33 \pm 8.7$ & $32.3 \pm 7$ & 0.632 \\
Serum potassium, mmol/L & $4.2 \pm 0.4$ & $4.2 \pm 0.3$ & 0.815 \\
Serum sodium, mmol/L & $138.4 \pm 1.4$ & $138.4 \pm 1.4$ & 0.852 \\
Serum total cholesterol, mg/dL & $185.1 \pm 40.1$ & $191.9 \pm 48.6$ & 0.419 \\
Serum LDL-cholesterol, mg/dL & $119.5 \pm 31.7$ & $126.2 \pm 39.5$ & 0.321 \\
Serum HDL-cholesterol, mg/dL & $52.3 \pm 11.6$ & $49.9 \pm 10.5$ & 0.260 \\
HbAlc, \% & $5.2 \pm 0.3$ & $5.2 \pm 0.3$ & 0.437 \\
Uric acid, mg/dL & $6.1 \pm 0.9$ & $6.0 \pm 1.2$ & 0.593 \\
Hematocrit, \% & $44 \pm 2.4$ & $44 \pm 2.6$ & 0.931 \\
\hline
\end{tabular}

Data are given as mean $\pm \mathrm{SD}$. BP, blood pressure; $\mathrm{HR}$, heart rate; bpm, beats per minute; eGFR, estimated glomerular filtration rate; BUN, blood urea nitrogen; LDL, low-density lipids; HDL, high-density lipids.

tributed parameters, the nonparametric test (Mann-Whitney U test) was used for further analysis. Covariance analyses were performed using univariate linear analysis. Adjustments were made for age since significant difference between the groups were noted. Two-tailed values of $p<0.05$ were considered statistically significant. All analyses were performed using IBM SPSS Statistics 22 (SPSS Inc., Chicago, IL, USA).

\section{Results}

\section{Study Population}

The clinical characteristics of individuals annoyed and not annoyed to noise are summarized in Table 1. Noise annoyance was graded from 1 to 7 , and the median of all rankings was 4 (interquartile range 1). The noise-annoyed study cohort comprised 58 male individuals aged $34 \pm 9.7$ years, and the non-noise-annoyed study cohort comprised 55 male individuals aged $29.9 \pm 9.5$ years. Both systolic and diastolic office BP were not significantly different between the groups. The estimated GFR based on creatinine and cystatin $\mathrm{C}$ was similar in both groups.

\section{Renal Hemodynamic Parameters}

Noise-annoyed individuals showed lower RPF (599 \pm 106 vs. $663 \pm 124 \mathrm{~mL} / \mathrm{min}, p=0.009$; Fig. 1), lower renal

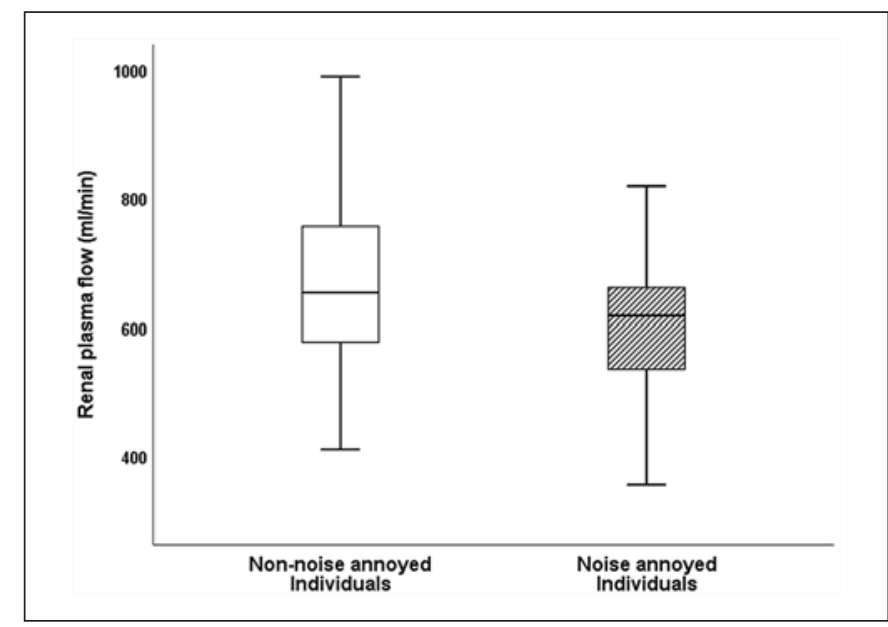

Fig. 1. Comparison of RPF between non-noise-annoyed and noiseannoyed individuals. The first boxplot shows RPF of individuals not annoyed to noise, and the second boxplot shows RPF of individuals annoyed to noise. Raw $p$ value $=0.009$; age-adjusted $p$ val$\mathrm{ue}=0.020$. RPF, renal plasma flow.

blood flow $(1,068 \pm 203$ vs. $1,172 \pm 225 \mathrm{~mL} / \mathrm{min}, p=$ $0.047)$, higher filtration fraction $(22.7 \pm 3.3$ vs. $21.3 \pm 3.0$, $p=0.012)$, higher renal vascular resistance $(88.9 \pm 25.6 \mathrm{vs}$. $75.8 \pm 22.9 \mathrm{~mm} \mathrm{Hg} /[\mathrm{mL} / \mathrm{min}], p=0.002$; Fig. 2), and 
higher resistance of afferent arteriole $(2,439.5 \pm 1,253.4$ vs. $1,849.9 \pm 1,242.0$ dyn s$^{-1} \mathrm{~cm}^{-5}, p=0.001$ ) compared to non-noise-annoyed individuals. There was no difference in GFR ( $133 \pm 12$ vs. $138 \pm 15 \mathrm{~mL} / \mathrm{min}, p=0.181)$, resistance of efferent arteriole $(2,419.4 \pm 472.2$ vs. $2,245.8 \pm$ 370.3 dyn s$\left.^{-1} \mathrm{~cm}^{-5}, p=0.060\right)$, and intraglomerular pressure ( $64.0 \pm 3.1$ vs. $64.6 \pm 3.5 \mathrm{~mm} \mathrm{Hg}, p=0.298)$ between noise-annoyed and non-noise-annoyed individuals.

After adjusting for age (Table 2), RPF (adjusted $p=$ 0.020 ), renal blood flow (adjusted $p=0.045$ ), and renal vascular resistance (adjusted $p=0.037$ ) remained significantly different between the groups. A trend in increase of resistance of afferent arteriole (adjusted $p=0.097$ ) and filtration fraction (adjusted $p=0.060$ ) was detected. There was no difference with respect to resistance of efferent arteriole (adjusted $p=0.128$ ).

We found a correlation between RPF $(r=0.188, p=$ 0.046 ) and subjective grading of noise annoyance for the entire cohort. Similar correlations have been observed with respect to filtration fraction $(r=-0.202, p=0.032)$, renal vascular resistance ( $r=-0.247, p=0.009$; Fig. 3 ), and resistance of afferent arteriole $(r=-0.287, p=0.002$; Fig. 3). This correlation has not been found for GFR, renal blood flow, intraglomerular pressure, and efferent renal resistance.

\section{Discussion}

The burden of noise on health is well described [11]. However, data regarding the effect of noise annoyance on health, in particular on the kidneys, are scarce. To the best of our knowledge, no data are available analyzing the renal hemodynamic profile in detail in individuals annoyed to noise. We measured renal perfusion and glomerular function by applying the steady-state input clearance technique, considered to be the gold standard. The main novel finding of this study is that noise annoyance is associated with changes in renal hemodynamics (Fig. 4). We found a significant difference in RPF and renal blood flow without any change in GFR between individuals annoyed and not annoyed to noise. This difference in flow may be attributed to higher renal vascular resistance predominantly at the afferent site, since renal vascular resistance and renal afferent resistance correlated closely with the level of noise annoyance.

Shih-Ho Lue et al. [28] observed a lower estimated GFR in patients living closer to a major roadway than in patients living farther away. The renal function decreased almost exponentially with increasing residential proximity to the

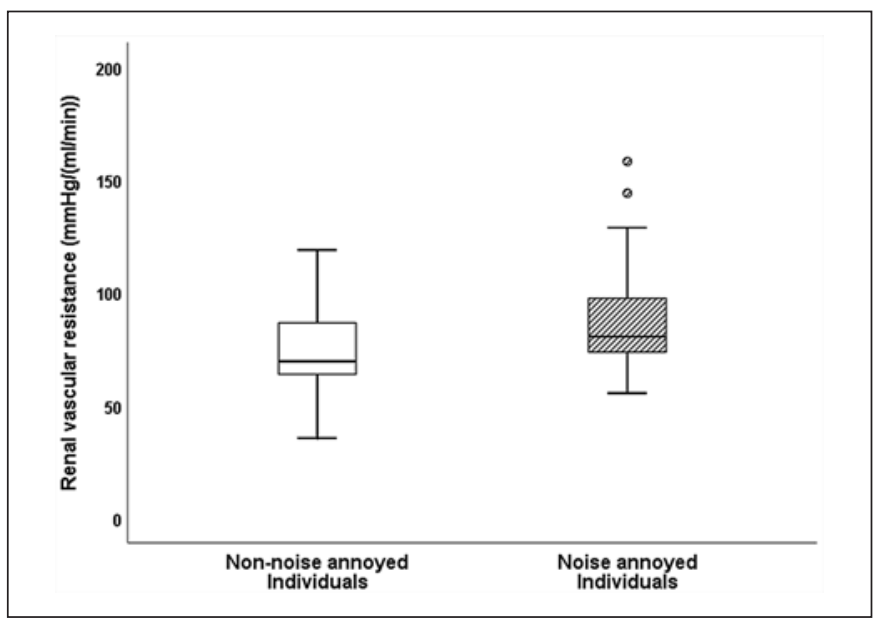

Fig. 2. Comparison of renal vascular resistance between nonnoise-annoyed and noise-annoyed individuals. The first boxplot shows renal vascular resistance of individuals not annoyed to noise, and the second boxplot shows renal vascular resistance of individuals annoyed to noise. Raw $p$ value $=0.002$; age-adjusted $p$ value $=0.037$.

major roadway. The study population comprised patients hospitalized with acute ischemic stroke. We found no reduction in measured GFR in our individuals annoyed to noise. The difference in study population might account for this discrepancy. Our study cohort comprised younger individuals with a mean age of 34 years without any evidence of severe end-organ damage. In accordance with our results, another study described a lack of association between global noise annoyance and estimated GFR in patients with CVD [29]. A reduction in RPF is noticed at early stages of various CVDs, including arterial hypertension $[30,31]$ with consequent reduction in GFR in the course of the disease [32]. We therefore hypothesize that noise annoyance in the early stage leads to increased renal afferent resistance and reduced renal perfusion, as evidenced in our cross-sectional study that translates to CKD at later stages of regular noise annoyance [33]. This should be verified in future longitudinal studies.

Renal autoregulatory mechanisms, including myogenic response of smooth muscles in response to stretching force, play a crucial role to maintain intraglomerular filtration pressure and to keep glomerular injury at minimum in CVDs [34]. This mechanism might not explain the reduced RPF in our noise-annoyed individuals, since both systolic and diastolic BP were not different between the groups. Increased activity of the sympathetic nervous system might be another mechanism by which noise-induced stress triggers renal hemodynamic changes. A 
Table 2. Renal hemodynamic parameters

\begin{tabular}{lccc}
\hline Renal parameters & $\begin{array}{l}\text { Non-noise-annoyed } \\
\text { individuals }\end{array}$ & $\begin{array}{l}\text { Noise-annoyed } \\
\text { individuals }\end{array}$ & $\begin{array}{l}\text { Age-adjusted } \\
p \text { value }\end{array}$ \\
\hline $\mathrm{RPF}, \mathrm{mL} / \mathrm{min}$ & $663 \pm 124$ & $599 \pm 106$ & 0.020 \\
Renal blood flow, $\mathrm{mL} / \mathrm{min}$ & $1,172 \pm 225$ & $1,068 \pm 203$ & 0.045 \\
GFR, $\mathrm{mL} / \mathrm{min}$ & $138 \pm 15$ & $133 \pm 12$ & 0.122 \\
GFR, $\mathrm{mL} / \mathrm{min}$ per $1.73 \mathrm{~m}^{2}$ & $120 \pm 19$ & $114 \pm 16$ & 0.209 \\
Filtration fraction & $21.3 \pm 3.0$ & $22.7 \pm 3.3$ & 0.060 \\
Renal vascular resistance, $\mathrm{mm} \mathrm{Hg} /(\mathrm{mL} / \mathrm{min})$ & $75.8 \pm 22.9$ & $88.9 \pm 25.6$ & 0.037 \\
RA, dyn s $\mathrm{cm}^{-5}$ & $1,849.9 \pm 1,242$ & $2,439.5 \pm 1,253.4$ & 0.097 \\
RE, dyn s $\mathrm{cm}^{-5}$ & $2,245.8 \pm 370.3$ & $2,419.4 \pm 472.2$ & 0.128 \\
Intraglomerular pressure, $\mathrm{mm} \mathrm{Hg}$ & $64.6 \pm 3.5$ & $64.0 \pm 3.1$ & 0.486 \\
\hline
\end{tabular}

Data are given as mean \pm SD. RPF, renal plasma flow; GFR, glomerular filtration rate (measured by inulin clearance); RA, resistance of afferent arteriole; RE, resistance of efferent arteriole.

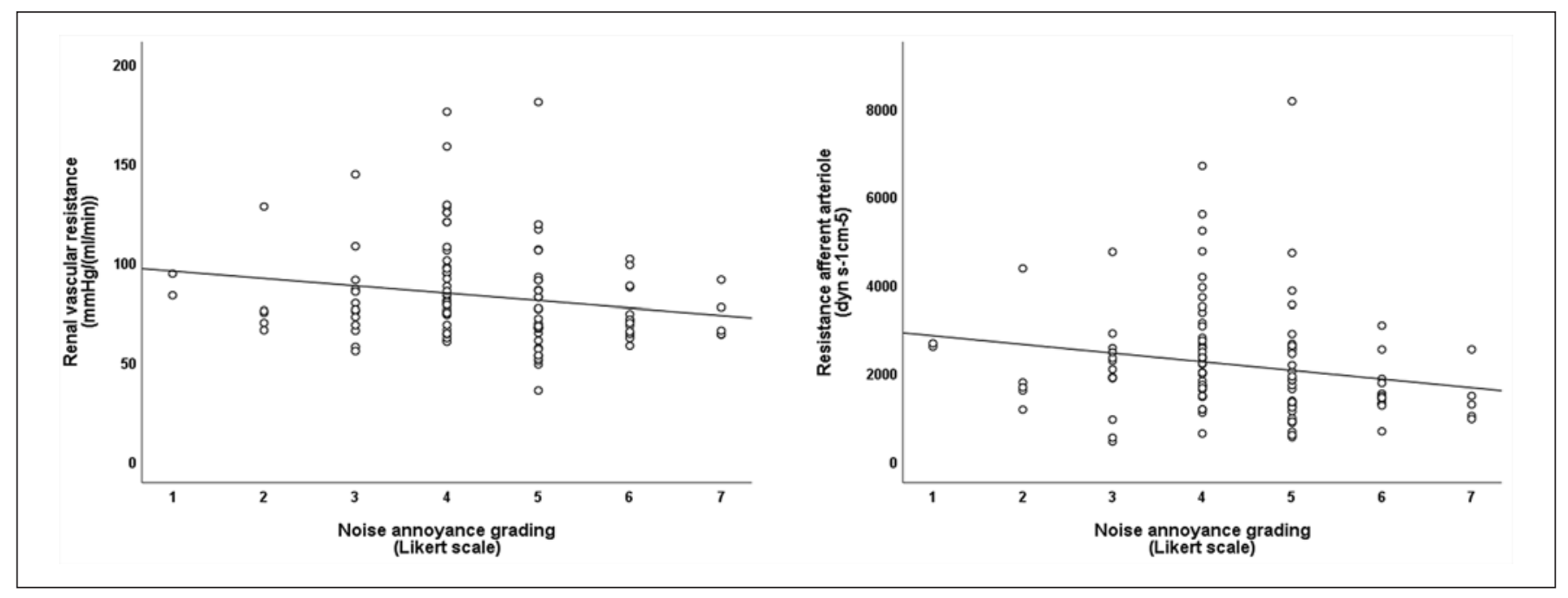

Fig. 3. Relationship between renal vascular resistance, resistance of afferent arteriole, and perceived noise annoyance ranked on a 7 -grade Likert scale $(1=$ very much annoyed, $2=$ much annoyed, $3=$ clearly annoyed, $4=$ moderately annoyed, $5=$ a little annoyed, $6=$ very little annoyed, and $7=$ not annoyed). Renal vascular resistance: $r=-0.247, p$ value $=0.009$; resistance of afferent arteriole: $r=-0.287, p$ value $=0.002$.

number of studies have described increased sympathetic nerve activity responsiveness to stress in humans [35]. In rabbits exposed to noise stress, an increase in renal sympathetic nerve activity associated with a significant mean reduction in renal blood flow has been observed [36]. In support to the involvement of this pathophysiological mechanism, heart rate, sometimes used as a surrogate marker of sympathetic overdrive, was found to be elevated in our individuals annoyed to noise [37]. Similarly, higher heart rate response and extensive coronary arteriosclerosis could be demonstrated in monkeys exposed to a stressful situation [38].

Noise Annoyance and Renal Hemodynamic Change
Stress-induced sympathetic activation escalates reninangiotensin-aldosterone-system activity of the juxtaglomerular apparatus in the kidneys [39]. Noise-induced increase in angiotensin II levels has been described in mice [40]. Renal actions of angiotensin II mediated by the AT1 receptor include increased afferent and efferent arteriolar vasoconstriction, with increased effect reported on efferent arterioles, constriction of other renal vessels, including the arcuate and interlobular arteries and vasa recta, and then leading to reduced renal blood flow, which are extensively described [41, 42]. However, in microcirculatory experiments, renal sympathetic stimulation did not 


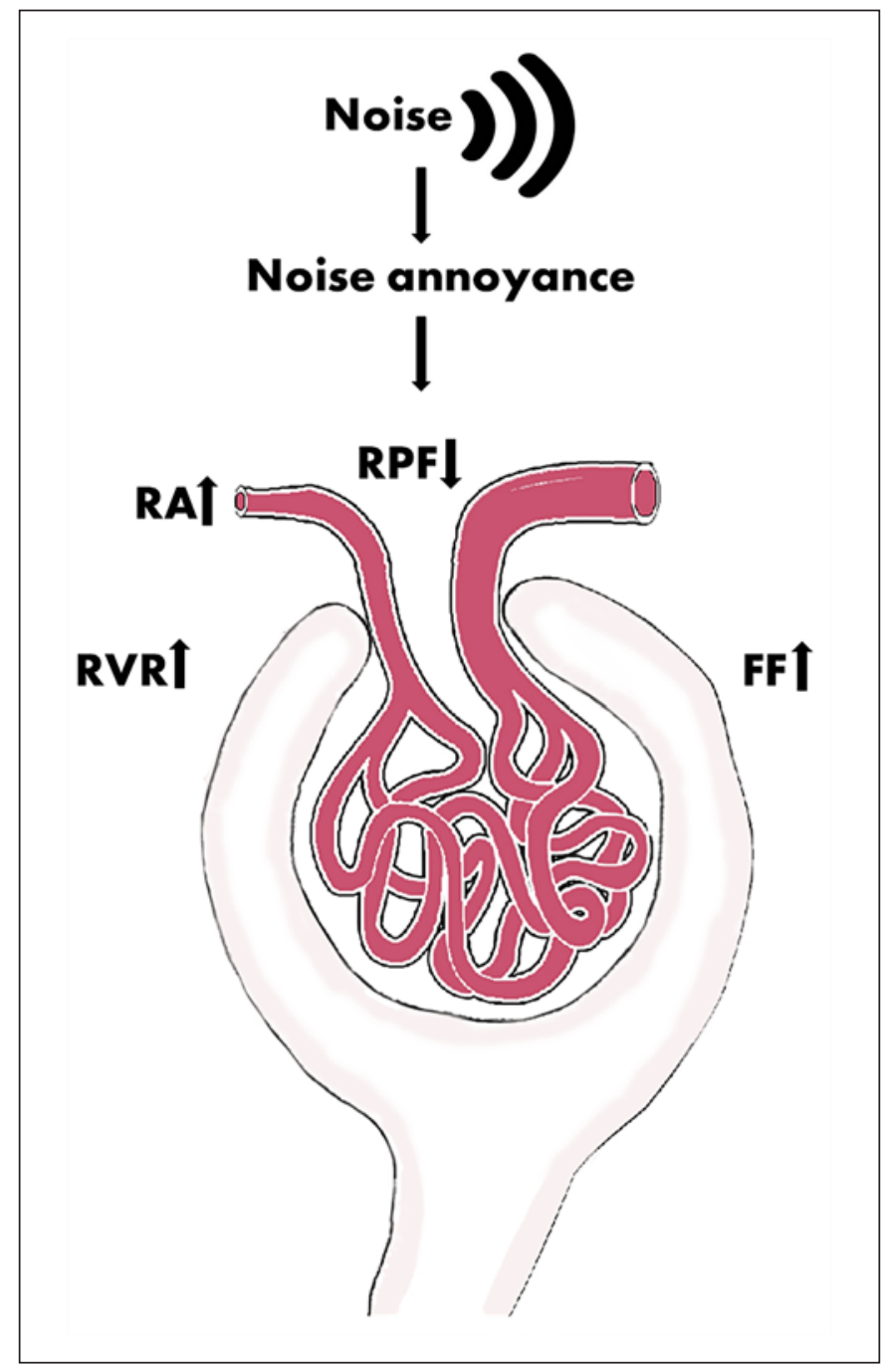

Fig. 4. Illustration of the effect of noise annoyance on renal hemodynamics. Directions of small arrows represent either increase or decrease of the renal parameters. RPF, renal plasma flow; RA, resistance of afferent arteriole; RVR, renal vascular resistance; FF, filtration fraction.

induce any constriction of efferent renal arterioles [43]. Similarly, we found no difference in renal efferent resistance between the groups. The higher renal vascular resistance found in the noise-annoyed individuals of our study is attributed to some extent to the higher renal afferent resistance and renal vessels other than the efferent arteriole. Angiotensin II-stimulated increase of endothelium-derived nitric oxide might have possibly buffered the vasoconstrictor actions of angiotensin II on renal afferent arterioles [44].

A country-wide meta-analysis showed that perceived stress is associated with daily smoking [45]. In a con- trolled study, Ritz et al. [46] demonstrated the effect of smoking on autonomous nervous system and renal hemodynamics. Smoking increased heart rate and renal vascular resistance in smokers similar to our individuals annoyed to noise. Similarly, an increase in renal sympathetic nerve activity and a reduction in renal blood flow have been demonstrated in rabbits by administration of cigarette smoke [36]. However, the entire cohort of our study were nonsmokers, and thus smoking was not a confounder of our study results.

One of the limitations of the study is that we did not measure the level of stress hormones in our study cohort. Besides the activation of the autonomic nervous system, the hypothalamic-pituitary-adrenal axis is another prominent feature of a stress response [14]. Measurement of stress hormones such as cortisol might have helped us further to explain the mechanisms behind the renal hemodynamic changes [47]. However, it has been demonstrated that intrarenal administration of cortisol had no effect on renal blood flow [48]. Another limitation is that we analyzed noise annoyance using a 7-grade Likert scale. The analysis of chronic mental stress is complex and difficult. The use of a more complex questionnaire including frequency of annoyed noise exposure, source of annoyed noise, noise level causing annoyance, and analysis of other environmental and nonenvironmental stress factors causing annoyance might have helped to better characterize the perceived burden of stress in our cohort. Thirdly, the parameters intraglomerular pressure and resistance of the afferent and efferent arteriole were not measured, but calculated based on the Gomez equations, since the human renal microcirculation cannot be assessed directly. However, the Gomez calculations have been repeatedly applied and appear to be reliable in humans with and without renal disease $[22,27]$. Finally, the observational nature of our study does not allow us to definitely establish the direction of the link between noise annoyance and renal hemodynamic changes.

\section{Conclusion}

In this study, noise annoyance was associated with reduced renal perfusion attributed to increased renal vascular resistance. This prompts speculations if this novel mechanistic insight would determine environmental stressors as causative agents for many CKDs of unknown origin. However, it should be investigated in future longitudinal clinical trials, if this pathophysiological change in the kidneys progresses to $\mathrm{CKD}$. Our study might raise the awareness to 
environmental stressors, promote further research in this field, and consequently lead to the development of different measures to reduce the extent of noise pollution.

\section{Acknowledgements}

We gratefully acknowledge the expert technical assistance of Andrea Donhauser, Dorothea Bader-Schmieder, Ingrid Fleischmann, Kerstin Fröhlich-Endreß, Simone Pejkovic, Ulrike Heinritz, Wiebke Maurer, and Meera Mathew.

\section{Statement of Ethics}

Written informed consent was obtained from each patient before study inclusion. The study protocol was approved by the Local Ethics Committee (Application No. 68_16B, University of Erlangen-Nürnberg), and the study was conducted in accordance with the Declaration of Helsinki and the principles of good clinical practice guidelines.

\section{Conflict of Interest Statement}

The authors declare no conflicts of interest.

\section{Funding Sources}

This research did not receive any specific grant from funding agencies in the public, commercial, or not-for-profit sectors.

\section{Author Contributions}

D.K. contributed to acquisition, analysis, and interpretation of all data and wrote the manuscript. S.J. contributed to acquisition of data and discussion and reviewed the manuscript critically. C.O. contributed to conception of the study and discussion and reviewed the manuscript critically. K.S. contributed to acquisition of data and discussion and reviewed the manuscript critically. J.K. contributed to acquisition of data and discussion and reviewed the manuscript critically. R.E.S. designed the study and reviewed data and manuscript critically. A.B. contributed to conception and design of the study and reviewed data and manuscript critically. All authors gave full consent for publication.

\section{References}

1 Gullette EC, Blumenthal JA, Babyak M, Jiang W, Waugh RA, Frid DJ, et al. Effects of mental stress on myocardial ischemia during daily life. JAMA. 1997 May 21;277(19):1521-6.

2 Steptoe A, Kivimäki M. Stress and cardiovascular disease. Nat Rev Cardiol. 2012 Apr 3; 9(6):360-70.

3 Nabi H, Kivimäki M, Batty GD, Shipley MJ, Britton A, Brunner EJ, et al. Increased risk of coronary heart disease among individuals reporting adverse impact of stress on their health: the Whitehall II prospective cohort study. Eur Heart J. 2013 Sept;34(34):2697705.

4 Su S, Jimenez MP, Roberts CT, Loucks EB. The role of adverse childhood experiences in cardiovascular disease risk: a review with emphasis on plausible mechanisms. Curr Cardiol Rep. 2015 Oct; 17(10):88.

5 Yusuf S, Hawken S, Ounpuu S, Dans T, Avezum A, Lanas F, et al. Effect of potentially modifiable risk factors associated with myocardial infarction in 52 countries (the INTERHEART study): case-control study. Lancet. 2004 Sept 11-17;364(9438):937-52.

6 Kaplan JR, Manuck SB, Clarkson TB, Lusso FM, Taub DM. Social status, environment, and atherosclerosis in cynomolgus monkeys. Arteriosclerosis. 1982 Sept-Oct;2(5):359-68.

7 Clarkson TB, Kaplan JR, Adams MR, Manuck SB. Psychosocial influences on the pathogenesis of atherosclerosis among nonhuman primates. Circulation. 1987 Jul;76(1 Pt 2):I29_ 40.
8 Lusis AJ. Atherosclerosis. Nature. 2000 Sept 14;407(6801):233-41.

9 Stallen PJ. A theoretical framework for environmental noise annoyance. Noise Health. 1999;1(3):69-80.

10 https: //www.umweltbundesamt.de/themen/ verkehrlaerm/laermwirkung/laermbelaestigung. Umweltbundesamt 2014; 2014.

11 World Health Organization. Burden of disease from environmental noise. Quantification of healthy life years lost in Europe. Bonn, Germany: World Health Organization (WHO); 2011.

12 Babisch W. Transportation noise and cardiovascular risk: updated review and synthesis of epidemiological studies indicate that the evidence has increased. Noise Health. 2006 JanMar;8(30):1-29.

13 Ndrepepa A, Twardella D. Relationship between noise annoyance from road traffic noise and cardiovascular diseases: a metaanalysis. Noise Health. 2011 May-Jun;13(52): 251-9.

14 Babisch W. Stress hormones in the research on cardiovascular effects of noise. Noise Health. 2003 Jan-Mar;5(18):1-11.

15 Babisch W. Cardiovascular effects of noise. Noise Health. 2011 May-Jun;13(52):201-4.

16 Bruce MA, Beech BM, Sims M, Brown TN, Wyatt SB, Taylor HA, et al. Social environmental stressors, psychological factors, and kidney disease. J Investig Med. 2009 Apr; 57(4):583-9.
17 Bruce MA, Griffith DM, Thorpe RJ Jr. Stress and the kidney. Adv Chronic Kidney Dis. 2015 Jan;22(1):46-53.

18 DiBona GF. Neural control of the kidney: past, present, and future. Hypertension. 2003 Mar;41(3 Pt 2):621-4.

19 Mancia G, Fagard R, Narkiewicz K, Redon J, Zanchetti A, Böhm M, et al. 2013 ESH/ESC practice guidelines for the management of arterial hypertension. Blood Press. 2014 Feb; 23(1):3-16.

20 Schmieder RE, Gatzka C, Schobel H, Schächinger $\mathrm{H}$, Weihprecht $\mathrm{H}$. Renal hemodynamic response to stress is influenced by ACE-inhibitors. Clin Nephrol. 1994 Dec;42(6):3818.

21 Guidi E, Cozzi MG, Minetti EE, Civati G, Busnach G, Brando B. Effect of familial hypertension on glomerular hemodynamics and tubulo-glomerular feedback after uninephrectomy. Am J Hypertens. 2001 Feb;14(2): 121-8.

22 Ott C, Schneider MP, Raff U, Ritt M, Striepe $\mathrm{K}$, Alberici M, et al. Effects of manidipine vs. amlodipine on intrarenal haemodynamics in patients with arterial hypertension. Br J Clin Pharmacol. 2013 Jan;75(1):129-35.

23 Tsuda A, Ishimura E, Uedono $\mathrm{H}$, Ochi A, Nakatani S, Morioka T, et al. Association of albuminuria with intraglomerular hydrostatic pressure and insulin resistance in subjects with impaired fasting glucose and/or impaired glucose tolerance. Dia Care. 2018 Nov; 41(11):2414-20. 
24 Ott C, Bosch A, Winzer N, Friedrich S, Schinzel R, Tegtmeier F, et al. Effects of the nitric oxide synthase inhibitor ronopterin (VAS203) on renal function in healthy volunteers. Br J Clin Pharmacol. 2019 May;85(5): 900-7.

25 Tsuda A, Ishimura E, Machiba Y, Uedono H, Nakatani S, Mori K, et al. Increased glomerular hydrostatic pressure is associated with tubular creatinine reabsorption in healthy subjects. Kidney Blood Press Res. 2020;45(6): 996-1008.

26 Gomez DM. Evaluation of renal resistances, with special reference to changes in essential hypertension. J Clin Invest. 1951 Oct;30(10): 1143-55.

27 Ott C, Ritt M, Titze SI, Schäufele T, Schmieder RE. Rosuvastatin does not affect intrarenal hemodynamics in patients with hypercholesterolemia. J Nephrol. 2009 Sept-Oct;22(5): 675-81.

28 Lue SH, Wellenius GA, Wilker EH, Mostofsky E, Mittleman MA. Residential proximity to major roadways and renal function. J Epidemiol Community Health. 2013 Aug;67(8): 629-34.

29 Dzhambov AM, Tokmakova MP, Gatseva PD, Zdravkov NG, Gencheva DG, Ivanova NG, et al. Community noise exposure and its effect on blood pressure and renal function in patients with hypertension and cardiovascular disease. Folia Med. 2017 Sept 1;59(3):34456.

30 Schmieder RE, Schächinger H, Messerli FH. Accelerated decline in renal perfusion with aging in essential hypertension. Hypertension. 1994 Mar;23(3):351-7.

31 Bidani AK, Griffin KA. Long-term renal consequences of hypertension for normal and diseased kidneys. Curr Opin Nephrol Hypertens. 2002 Jan;11(1):73-80.
32 Carlström M, Wilcox CS, Arendshorst WJ. Renal autoregulation in health and disease. Physiol Rev. 2015 Apr;95(2):405-511.

33 Chade AR, Williams ML, Engel J, Guise E, Harvey TW. A translational model of chronic kidney disease in swine. Am J Physiol Renal Physiol. 2018 Aug 1;315(2):F364-F73.

34 Just A. Mechanisms of renal blood flow autoregulation: dynamics and contributions. Am J Physiol Regul Integr Comp Physiol. 2007 Jan;292(1):R1-17.

35 Carter JR, Goldstein DS. Sympathoneural and adrenomedullary responses to mental stress. Compr Physiol. 2015 Jan;5(1):119-46.

36 Malpas SC, Evans RG. Do different levels and patterns of sympathetic activation all provoke renal vasoconstriction? J Auton Nerv Syst. 1998 Mar 3;69(1):72-82.

37 Palatini P, Benetos A, Grassi G, Julius S, Kjeldsen SE, Mancia G, et al. Identification and management of the hypertensive patient with elevated heart rate: statement of a European Society of Hypertension Consensus Meeting. J Hypertens. 2006 Apr;24(4):603-10.

38 Manuck SB, Kaplan JR, Clarkson TB. Behaviorally induced heart rate reactivity and atherosclerosis in cynomolgus monkeys. Psychosom Med. 1983 May;45(2):95-108.

39 Groeschel M, Braam B. Connecting chronic and recurrent stress to vascular dysfunction: no relaxed role for the renin-angiotensin system. Am J Physiol Renal Physiol. 2011 Jan; 300(1):F1-10.

40 Münzel T, Daiber A, Steven S, Tran LP, Ullmann E, Kossmann S, et al. Effects of noise on vascular function, oxidative stress, and inflammation: mechanistic insight from studies in mice. Eur Heart J. 2017 Oct 1;38(37):2838-49.
41 Navar LG, Inscho EW, Majid SA, Imig JD, Harrison-Bernard LM, Mitchell KD. Paracrine regulation of the renal microcirculation. Physiol Rev. 1996 Apr;76(2):425-536.

42 Arendshorst WJ, Brännström K, Ruan X. Actions of angiotensin II on the renal microvasculature. J Am Soc Nephrol. 1999 Jan;10(Suppl 11):S149-61.

43 Fleming JT, Zhang C, Chen J, Porter JP. Selective preglomerular constriction to nerve stimulation in rat hydronephrotic kidneys. Am J Physiol. 1992 Mar;262(3 Pt 2):F348-53.

44 Ito S, Arima S, Ren YL, Juncos LA, Carretero $\mathrm{OA}$. Endothelium-derived relaxing factor/nitric oxide modulates angiotensin II action in the isolated microperfused rabbit afferent but not efferent arteriole. J Clin Invest. 1993 May; 91(5):2012-9.

45 Stubbs B, Veronese N, Vancampfort D, Prina AM, Lin PY, Tseng PT, et al. Perceived stress and smoking across 41 countries: a global perspective across Europe, Africa, Asia and the Americas. Sci Rep. 2017 Aug 8;7(1):7597.

46 Ritz E, Benck U, Franek E, Keller C, Seyfarth $\mathrm{M}$, Clorius J. Effects of smoking on renal hemodynamics in healthy volunteers and in patients with glomerular disease. J Am Soc Nephrol. 1998 Oct;9(10):1798-804.

47 Connell JM, Whitworth JA, Davies DL, Lever AF, Richards AM, Fraser R. Effects of ACTH and cortisol administration on blood pressure, electrolyte metabolism, atrial natriuretic peptide and renal function in normal man. J Hypertens. 1987 Aug;5(4):425-33.

48 van Uum SH, Houben AJ, Hermus AR, Kroon AA, Walker BR, Sweep CG, et al. Acute intrarenal administration of cortisol has no effect on renal blood flow in hypertensive individuals. J Hypertens. 2002 Nov;20(11):2275-83. 